\title{
POLYHERBAL PREPARATION AND COMPARATIVE STUDIES ON DIET-INDUCED HYPERLIPIDEMIA
}

\author{
NUZHAT QURESHI ${ }^{1 *}$, RAGHVENDRA DUBEY ${ }^{1}$, NILESH KUMAR PATHAK ${ }^{2}$ \\ ${ }^{1}$ Department of Pharmacology, College of Pharmacy, Indore, Madhya Pradesh, India, ${ }^{2}$ Department of Pharmacology, Royal Institute of \\ Management and Advanced Studies, Ratlam, Madhya Pradesh, India. Email: nuzhatq50@gmail.com
}

Received: 11 July 2019, Revised and Accepted: 27 September 2019

\section{ABSTRACT}

Objective: The objective of this research article is to develop and evaluate polyherbal preparation and comparative studies on diet-induced hyperlipidemia.

Methods: After the extraction, pharmacognostical and phytochemical screening was done. The lipid-lowering activity of polyherbal formulation (T1, T2, T3, T4, and T5) may be attributed to the phytoconstituents present such as alkaloids, carbohydrates, steroids, proteins, tannins, carbohydrates, flavonoids, phenols, glycosides, and triterpenes. In acute oral toxicity study, there were no behavioral changes seen up to $4 \mathrm{~h}$ and no mortality was observed up to the end of 24 h even at the maximum tested dose level of $2000 \mathrm{mg} / \mathrm{kg}$ per oral. It was considered maximum safe dose. Male and female albino rats weighing 150-200 g were used for the study. Hydroalcoholic extract of all plants was prepared having a dose of $2000 \mathrm{mg} / \mathrm{kg}$. The doses were selected according to the Organisation for Economic Cooperation and Development guideline no. 425. The procedure was divided into two phases: Phase I (observation made on day 1) and Phase II (observed the animals for the next 14 days of drug administration). Animals received a single dose of $2000 \mathrm{mg} / \mathrm{kg}$. After the administration of Healthcare Administration, food was withheld for 3-4 h. In case animal dies, we have to again perform the test for the determination of $\mathrm{LD}_{50}$. The study was conducted by measuring various parameters, namely, daily feed intake (g), water intake (ml), body weight (g), lipid profile high-density lipoprotein (HDL), low-density lipoprotein (LDL), Cholesterol (CHL) level (mg/dl), and blood glucose level (mg/dl).

Results: Results showed a significant decrease in blood glucose level and serum lipid profile such as total cholesterol, LDL, and increasing serum HDL level, so could be useful in the treatment of hypolipidemia.

Conclusion: Polyherbal formulations (T1, T2, T3, T4, and T5) have hypoglycemic activity and significantly improve lipid profile levels in diet-induced experimental rats.

Keywords: Hyperlipidemia, Atherosclerosis, Allium sativum, Moringa oleifera, Cicer arietinum, Hibiscus rosa-sinensis, Quisqualis indica.

(C) 2019 The Authors. Published by Innovare Academic Sciences Pvt Ltd. This is an open access article under the CC BY license (http://creativecommons. org/licenses/by/4. 0/) DOI: http://dx.doi.org/10.22159/ajpcr.2019.v12i12.34872

\section{INTRODUCTION}

Hyperlipidemia is known as a condition of an increased level of serum total cholesterol (TC), low-density lipoprotein (LDL), very LDL (VLDL), and reduced high-density lipoprotein (HDL) [1].

Cardiovascular diseases (CVDs) are a major risk factor caused by hyperlipidemia. Hyperlipidemia disease has afflicted humankind since antiquity. Hyperlipidemia, or hyperlipoproteinemia, is defined as abnormally elevated levels of one or more of triglycerides, cholesterol, cholesterol esters, and phospholipids and plasma lipoproteins including VLDL and LDL, and reduced HDL levels. These lipoproteins are deposit in the interstitial space of arteries arising from aorta, restricting the blood supply to the heart. This phenomenon is known as atherosclerosis. Due to the privilege deposition of lipoproteins, blood supply to the heart gets blocked, and thus, myocardial infarction occurs, which is usually well known as heart attack.

Among ischemic heart disease and the high mortality rate, there is a strong relation. In addition, high plasma cholesterol levels cause more than 4 million deaths in a year. Secondary hyperlipidemia often mimics familial forms of hyperlipidemia and can have similar effects. Due to secondary hyperlipidemia, risk of premature atherosclerosis increased or, when happen with severe hypertriglyceridemia, may cause pancreatitis and other consequences of the chylomicronemia syndrome [2,3].

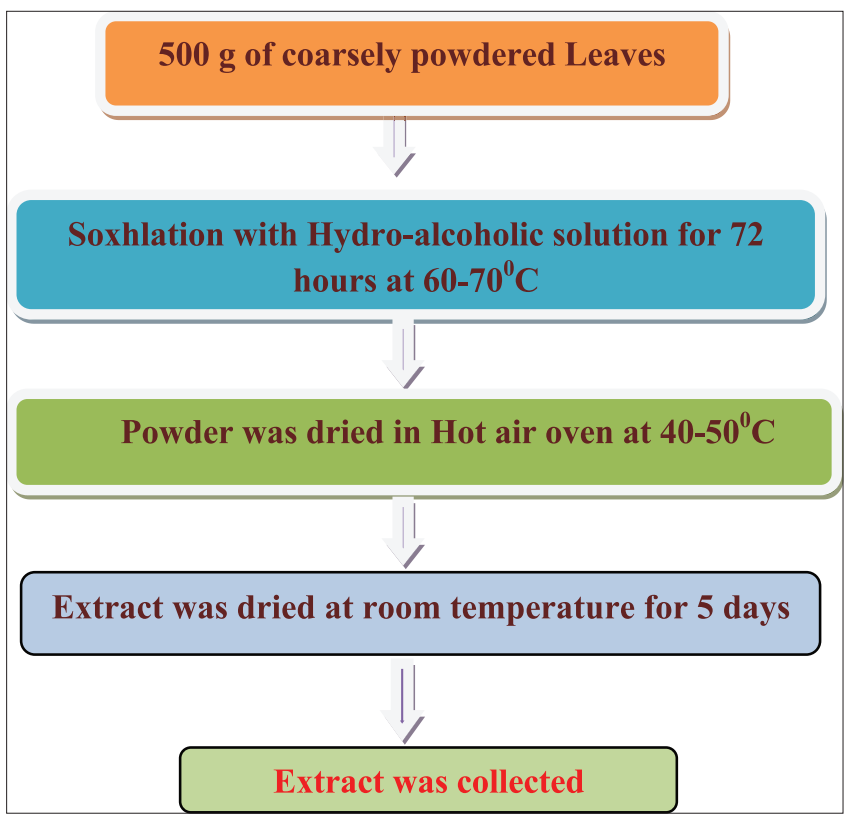

Fig. 1: Soxhlet extraction of plant parts $[17,18]$ 
From times of yore, several studies have shown that dietary modifications such as high-fiber diets, low-fat diets, and diets rich in flavonoids and phenolic acids can reduce metabolic syndrome

Table 1: Animals were grouped as follows

\begin{tabular}{ll}
\hline Group I & Normal control group (normal diet [ND]) \\
Group II & Positive control group (ND+HFHSD) \\
Group III & Standard control group (HFHSD+ND+atorvastatin \\
& calcium [2.1 mg/kg, p.o. body weight]) \\
Group IV & Test control group (HFHSD+ND+polyherbal \\
& formulation [300 mg/kg, p.o. body weight]) \\
\hline
\end{tabular}

HFHSD: High-fat high-sugar diet risk factors. Statins and synthetic antioxidants such as probucol are modern antihyperlipidemic drugs which are widely used to treat atherosclerosis. Regrettably, these drugs are not free of side effects. To provide novel treatments for hyperlipidemia, it has been focused on the natural products that have very few side effects [4-6].

Herbs have a defined kind of potency through which they can stimulate the human body to protect itself against the diseases. These medicinal herbs serve as a great source of remedies in the treatment of human and animal diseases [7].

Here, we are in progress to prepare a polyherbal formulation which consists of the extract of Allium sativum, Moringa oleifera, Cicer

Table 2: Morphological characteristics of plants part

\begin{tabular}{|c|c|c|c|c|c|c|}
\hline \multirow[t]{2}{*}{ S. No. } & \multirow[t]{2}{*}{ Character } & \multicolumn{5}{|c|}{ Observation } \\
\hline & & T1 & T2 & T3 & T4 & T5 \\
\hline 1. & Color & Green & Green & Green & Deep green & Green \\
\hline 3. & Taste & Pungent & Better to ingest & Sweet & Edible tangy citrusy & Simple \\
\hline 4. & Size & $5-150 \mathrm{~cm}$ & $2-5 \mathrm{~cm}$ & $0.5-3 \mathrm{~cm}$ & $6.0^{\prime \prime}$ length & $5-10 \mathrm{~cm}$ \\
\hline
\end{tabular}

T1: Allium sativum, T2: Moringa oleifera, T3: Cicer arietinum, T4: Hibiscus rosa-sinensis, T5: Quisqualis indica

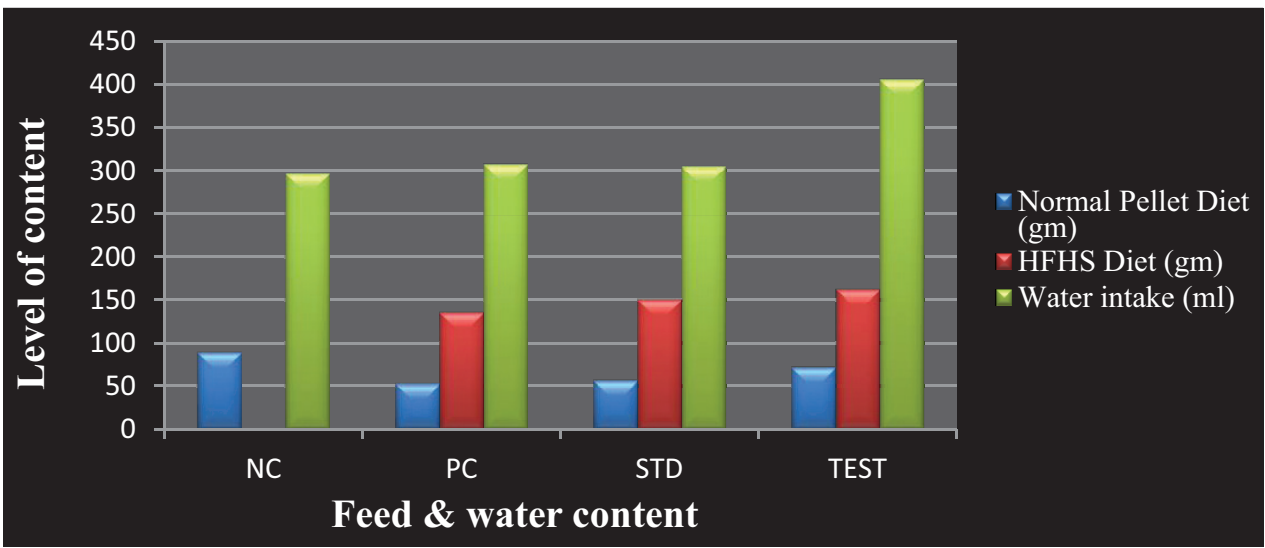

Graph 1: Effect of high-fat high-sugar diet on total feed and water content. Values are expressed as mean \pm standard deviation; ( $n=6)$. All values are mean \pm standard error of mean, $n=6 .{ }^{*} p<0.05,{ }^{* *} \mathbf{p}<0.01$ when compared to positive control group, following repeated measures ANOVA parametric methods, using Dunnett's test

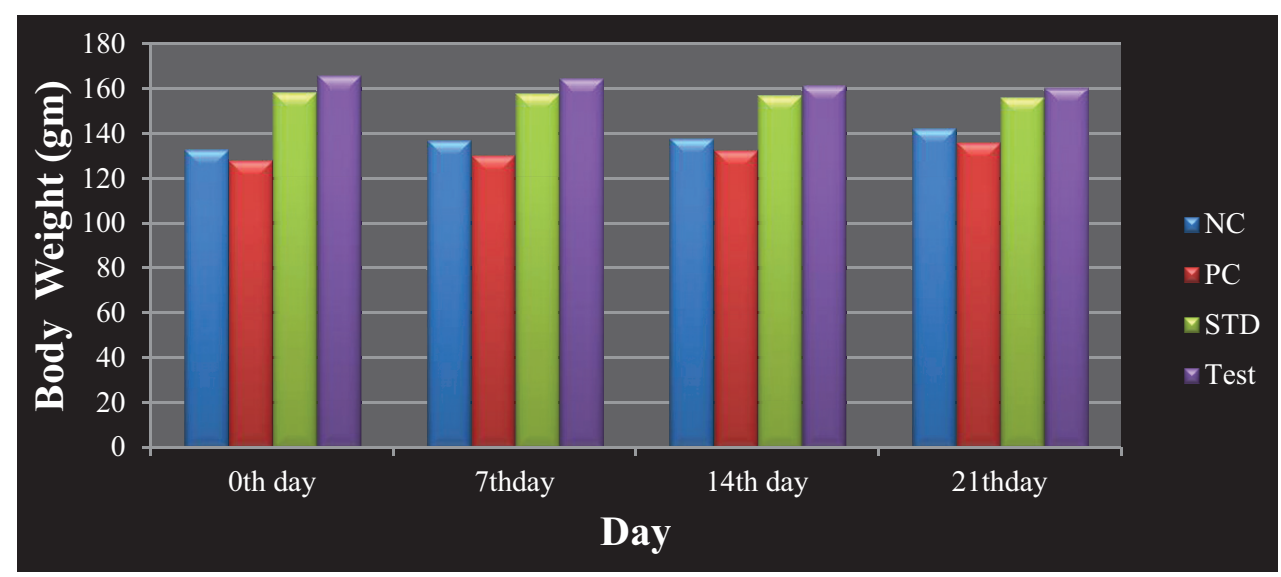

Graph 2: Effect of high-fat high-sugar diet, atorvastatin, and Cordia dichotoma on body weight. Values are expressed as mean \pm standard deviation; $(n=6)$. All values are mean \pm standard error of mean, $n=6$. ${ }^{*} p<0.05,{ }^{* *} p<0.01$ when compared to positive control group. Following repeated measures ANOVA parametric methods, using Dunnett's test. NC: Normal control group, PC: Positive control group or high-fat high-sugar diet group, standard: ND+high-fat high sugar (HFHS)+atorvastatin $(2.1 \mathrm{mg} / \mathrm{kg} / \mathrm{day})$, test control: ND+HFHS+polyherbal formulation $(300 \mathrm{mg} / \mathrm{kg} / \mathrm{day})$ 
arietinum, Hibiscus rosa-sinensis, and Quisqualis indica for the treatment of hyperlipidemia.

Garlic (A. sativum L., family: Alliaceae) has played significant medicinal and dietary roles throughout the ages. A. sativum (Garlic) preparations are commercially available in the form of garlic oil and garlic powder, and pills are widely used for certain therapeutic purposes, including improving lipid profile and lowering blood pressure. Extract of A. sativum is alleged to possess valuable effects for the prevention of CVDs. Garlic contains active hypocholesterolemic and hypoglycemic

Table 3: Consistency and color of all plant extracts

\begin{tabular}{llll}
\hline Extract & Solvent uses & Color & Consistency \\
\hline T1 & Hydroalcoholic & Dark green & Semi-solid \\
T2 & Hydroalcoholic & Black & Semi-solid \\
T3 & Hydroalcoholic & Black & Semi-solid \\
T4 & Hydroalcoholic & Dark green & Semi-solid \\
T5 & Hydroalcoholic & Dark green & Semi-solid \\
\hline
\end{tabular}

T1: Allium sativum, T2: Moringa oleifera, T3: Cicer arietinum,

T4: Hibiscus rosa-sinensis, T5: Quisqualis indica

Table 4: Percentage yield of all plant extracts

\begin{tabular}{llll}
\hline S. No. & Extracts & Yield $\mathbf{( g )}$ & Percentage yield (\%) \\
\hline 1. & T1 & 12.801 & 14.94 \\
2. & T2 & 11.502 & 12.50 \\
3. & T3 & 13.200 & 15.20 \\
4. & T4 & 15.020 & 16.25 \\
5. & T5 & 14.250 & 13.65 \\
\hline
\end{tabular}

T1: Allium sativum, T2: Moringa oleifera, T3: Cicer arietinum,

T4: Hibiscus rosa-sinensis, T5: Quisqualis indica

Table 5: Physiochemical analysis of powder of all plant leaves

\begin{tabular}{|c|c|c|c|c|c|c|}
\hline \multirow[t]{2}{*}{ S. No. } & \multirow[t]{2}{*}{ Parameters } & \multicolumn{5}{|c|}{ Observation (\%) } \\
\hline & & T1 & T2 & T3 & T4 & T5 \\
\hline 1. & Loss on drying & 1.58 & 2.05 & 1.35 & 1.55 & 1.75 \\
\hline 2. & Total ash value & 4.50 & 3.80 & 3.59 & 4.89 & 3.74 \\
\hline 3. & $\begin{array}{l}\text { Acid-insoluble } \\
\text { ash value }\end{array}$ & 0.85 & 1.05 & 0.95 & 1.00 & 1.10 \\
\hline 4. & $\begin{array}{l}\text { Water-soluble } \\
\text { ash value }\end{array}$ & 0.89 & 0.93 & 0.085 & 0.97 & 1.0 \\
\hline 5. & $\begin{array}{l}\text { Foaming } \\
\text { index }(\mathrm{cm})\end{array}$ & 1.00 & 1.25 & 0.62 & 0.5 & 0.45 \\
\hline
\end{tabular}

T1: Allium sativum, T2: Moringa oleifera, T3: Cicer arietinum,

T4: Hibiscus rosa-sinensis, T5: Quisqualis indica components, known as diallyl disulfide and dipropyl disulfide; it was proven by several studies [8-10].

Leaves of M. oleifera Lam., Moringaceae, are claimed to possess several pharmacological activities such as cholesterol-reducing effect and are used to treat patients with heart disease and antiobesity potential that protects the body against adverse effects of high-fat diet-induced obesity. The presence of $\beta$-sitosterol in crude extracts of $M$. oleifera possesses potential hypolipidemic properties $[11,12]$.

C. arientum reported a rich source of vitamins, minerals, and phytoestrogens. Seeds of $C$. arientum were used as stimulant, aphrodisiac, tonic, anthelminthic, appetizer, relieving burning sensation in stomach, and in the treatment of obesity and in patients who consume excess oily and heavy foods. Cholesterol-lowering effects of $C$. arientum in different types of hyperlipidemias such as induced by diet are demonstrated in several research studies [13].

H. rosa-sinensis Linn. flowers exhibited a significant reduction in serum lipid parameters such as triglycerides, TC, LDL, VLDL, and increase in HDL [14]

Cholesterol diet and passive smoking raise the lipid and cholesterol levels with reducing the HDL level which causes hypercholesterolemia and hyperlipidemia existing heart disease such as heart attack and heart stroke in the future. Q. indica Linn. raised the HDL level which is good cholesterol and produced a significant reduction in harmful lipids. $Q$. indica extracts contain flavonoids and phenolic compounds helpful in CVD $[15,16]$.

\section{METHODS}

\section{Collection of plant}

A. sativum, M. oleifera, C. arietinum, Q. indica, H. rosa-sinensis, and Q. indica were collected from various places from BHEL area, Govindpura, Bhopal, Madhya Pradesh, during the month of May 2018.

\section{Authentication of plant material}

The plant has been identified and authenticated by Janata PG College, A.P.S. University, Rewa, Madhya Pradesh, voucher specimen no. is Number/J/BOT/H-332 to H-336.

\section{Preparation of extract}

Extraction of A. sativum, M. oleifera, C. arietinum, Q. indica, H. rosasinensis, and Q. indica was done by Soxhlet extraction method (Fig. 1).

- Soxhlet extraction: Soxhlet apparatus was used for the extraction and hydroalcoholic solvent (1:1) was selected as a solvent for extraction and calculated percentage yield of the extract.

Table 6: Phytochemical screening of hydroalcoholic extract

\begin{tabular}{|c|c|c|c|c|c|c|c|}
\hline S. No. & Identification test & Test name & T1 & $\mathrm{T} 2$ & T3 & T4 & T5 \\
\hline \multirow[t]{3}{*}{1.} & Alkaloids & Mayer's test & + & + & - & + & + \\
\hline & & Dragendorff's test & + & - & + & + & - \\
\hline & & Wagner's test & + & + & - & + & + \\
\hline 2. & Glycosides & Killer-Killani test & + & + & + & - & + \\
\hline \multirow[t]{2}{*}{3.} & Carbohydrates & Molisch's test & - & - & + & + & + \\
\hline & & Fehling test & + & - & + & - & - \\
\hline 4. & Tannins and phenols & Gelatin test & + & + & + & + & + \\
\hline \multirow[t]{2}{*}{5.} & Flavonoids & Shinoda test & + & + & + & + & + \\
\hline & & Alkaline reagent test & - & + & + & + & + \\
\hline \multirow[t]{2}{*}{6} & Steroids & Liebermann-Burchard test & - & - & + & - & + \\
\hline & & Salkowski test & - & - & - & + & + \\
\hline 7. & Saponins & Foam test & + & + & - & - & - \\
\hline 8. & Protein & Xanthoproteic & + & - & + & + & + \\
\hline 9. & Gums and mucilage & With $95 \%$ alcohol & - & + & - & - & - \\
\hline
\end{tabular}




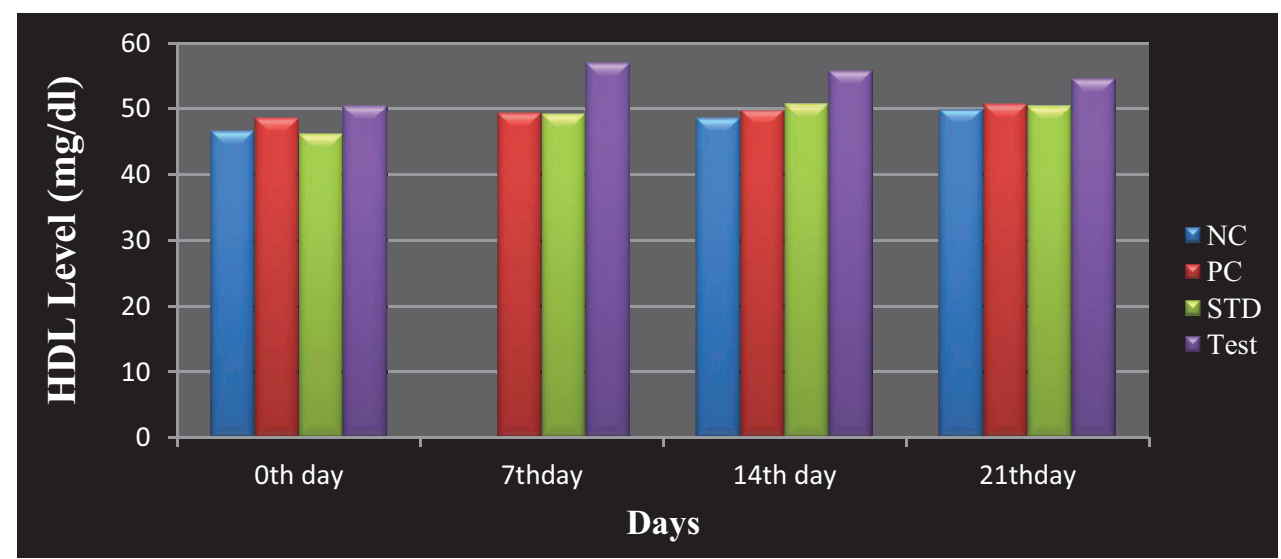

Graph 3: Effect of high-fat high-sugar diet, atorvastatin, and Cordia dichotoma on HDL level. Values are expressed as mean \pm standard deviation; $(n=6)$. All values are mean \pm standard error of mean, $n=6 .{ }^{*} p<0.05,{ }^{* *} \mathbf{p}<0.01$ when compared to positive control group. Following repeated measures ANOVA parametric methods, using Dunnett's test. NC: Normal control group, PC: Positive control group or high-fat high-sugar diet group, standard: ND+high-fat high sugar (HFHS)+atorvastatin ( $2.1 \mathrm{mg} / \mathrm{kg} /$ day), test control: ND+HFHS+polyherbal formulation $(300 \mathrm{mg} / \mathrm{kg} / \mathrm{day})$

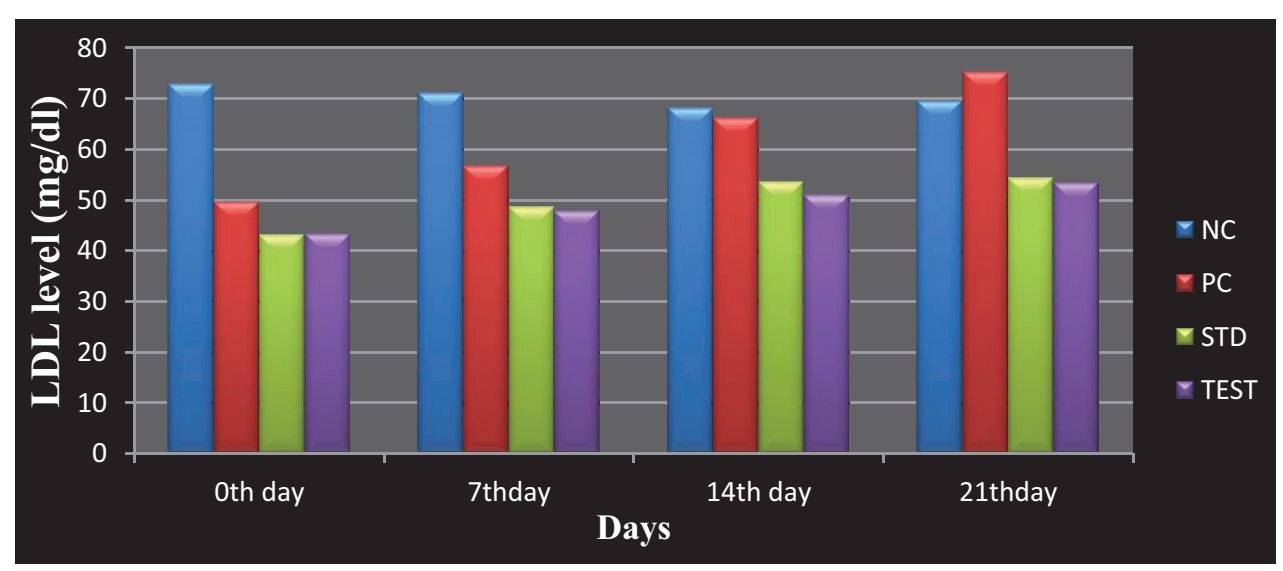

Graph 4: Effect of high-fat high-sugar diet, atorvastatin, and Cordia dichotoma on LDL level. Values are expressed as mean \pm standard deviation; $(n=6)$. All values are mean \pm standard error of mean, $n=6 .{ }^{*} p<0.05,{ }^{* *} p<0.01$ when compared to positive control group. Following repeated measures ANOVA parametric methods, using Dunnett's test. NC: Normal control group, PC: Positive control group or high-fat high-sugar diet group, standard: ND+high-fat high sugar (HFHS)+atorvastatin (2.1 mg/kg/day), test control: ND+HFHS+polyherbal formulation $(300 \mathrm{mg} / \mathrm{kg} /$ day $)$

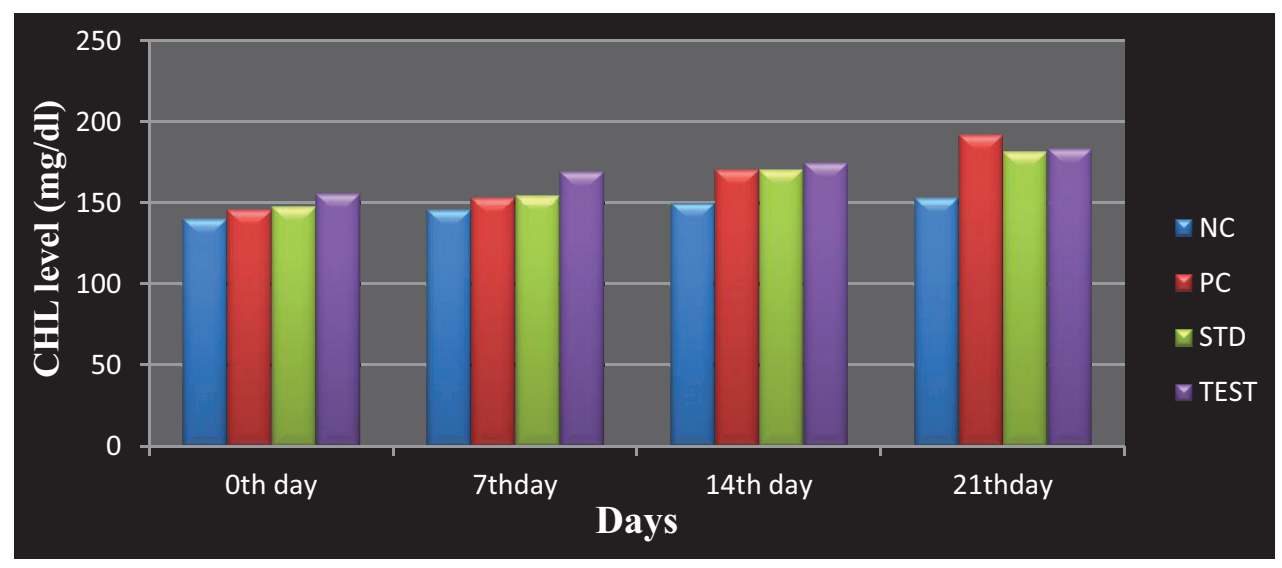

Graph 5: Effect of high-fat high-sugar diet, atorvastatin, and Cordia dichotoma on CHL level. Values are expressed as mean \pm standard deviation; $(n=6)$. All values are mean \pm standard error of mean, $n=6$. ${ }^{*} p<0.05,{ }^{* *} p<0.01$ when compared to positive control group. Following repeated measures ANOVA parametric methods, using Dunnett's test. NC: Normal control group, PC: Positive control group or high-fat high-sugar diet group, standard: ND+high-fat high sugar (HFHS)+atorvastatin $(2.1 \mathrm{mg} / \mathrm{kg} / \mathrm{day})$, test control: ND+HFHS+polyherbal formulation $(300 \mathrm{mg} / \mathrm{kg} / \mathrm{day})$ 
Table 7: Results of acute oral toxicity study of HACD

\begin{tabular}{|c|c|c|c|c|c|c|c|}
\hline \multirow{2}{*}{$\begin{array}{l}\text { Group } \\
\text { name }\end{array}$} & \multirow{2}{*}{$\begin{array}{l}\text { Animal } \\
\text { mark }\end{array}$} & \multirow[t]{2}{*}{ Dose mg/kg } & \multicolumn{3}{|c|}{ Body weight (g) } & \multirow[t]{2}{*}{ Observation } & \multirow[t]{2}{*}{ Mortality (if any) } \\
\hline & & & 1 day & 7 days & 14 days & & \\
\hline \multirow[t]{2}{*}{ Control } & $\mathrm{H}$ & Normal saline $(0.91 \%)$ & 153 & 148 & 146 & \multirow{5}{*}{$\begin{array}{l}\text { No sign of toxicity and } \\
\text { all animals survived }\end{array}$} & \multirow{5}{*}{ No mortality occurs } \\
\hline & $\mathrm{T}$ & & 138 & 135 & 132 & & \\
\hline \multirow[t]{3}{*}{ Test } & HT & $2000 \mathrm{mg} / \mathrm{kg}$ polyherbal formulation & 205 & 208 & 202 & & \\
\hline & $\mathrm{BT}$ & (once dosing at start of acute oral toxicity study) & 190 & 185 & 180 & & \\
\hline & NM & & 175 & 165 & 168 & & \\
\hline
\end{tabular}

Table 8: Total feed (g) and water (ml) intake

\begin{tabular}{llll}
\hline Group & $\begin{array}{l}\text { Normal } \\
\text { pellet diet } \mathbf{( g )}\end{array}$ & HFHSD (g) & $\begin{array}{l}\text { Water } \\
\text { intake (ml) }\end{array}$ \\
\hline NC & $89.38 \pm 27.53$ & 0 & $296.67 \pm 66.60$ \\
PC & $53.09 \pm 4.70^{*}$ & $135.73 \pm 18.41$ & $307.67 \pm 86.98^{* *}$ \\
STD & $57.08 \pm 21.13^{*}$ & $151.16 \pm 9.99$ & $305.00 \pm 51.57$ \\
Test & $72.40 \pm 12.78$ & $162.28 \pm 10.82$ & $406.33 \pm 20.88$ \\
\hline
\end{tabular}

All values are mean \pm standard error of mean, $\mathrm{n}=6 .{ }^{*} \mathrm{p}<0.05,{ }^{* *} \mathrm{p}<0.01$ when compared to positive control group. (Following repeated measures ANOVA (parametric methods, using Dunnett's test). HFHSD: High-fat high-sugar diet (Graph 1)

Table 9: Body weight (g)

\begin{tabular}{lllll}
\hline Group & $\mathbf{0}^{\text {th }}$ day & $\mathbf{7}^{\text {th }}$ day & $\mathbf{1 4}^{\text {th }}$ day & $\mathbf{2 1}^{\text {th }}$ day \\
\hline NC & $133.17 \pm 3.25$ & $137.5 \pm 3.20$ & $138.00 \pm 1.78$ & $142.66 \pm 1.36^{* *}$ \\
PC & $128.5 \pm 2.42$ & $130.8 \pm 2.63$ & $133.00 \pm 2.36$ & $136.33 \pm 1.67$ \\
STD & $158.5 \pm 2.88$ & $158.00 \pm 3.34$ & $157.33 \pm 3.07$ & $156.16 \pm 2.49$ \\
Test & $166.00 \pm 5.03^{*}$ & $164.83 \pm 4.53^{*}$ & $161.83 \pm 4.07^{*}$ & $160.83 \pm 4.35$ \\
\hline \multicolumn{7}{l}{ All values are mean \pm standard error of mean, $\mathrm{n}=6 .^{*} \mathrm{p}<0.05,{ }^{* *} \mathrm{p}<0.01$} \\
when compared to positive control group. (Following repeated measures
\end{tabular}

\section{Preparation of polyherbal formulation}

The hydroalcoholic extract of A. sativum (50 mg), M. oleifera (50 mg), C. arietinum (50 mg), H. rosa-sinensis $(50 \mathrm{mg})$, and Q. indica $(50 \mathrm{mg})$ was dissolved in suspending agent (1\% carboxymethylcellulose [CMC] aqueous) before orally administered to the rats. Standard drug was dissolved in suspending agent $(1 \% \mathrm{CMC})$ before orally administered to the rats [19].

\section{Preparation of high-fat high-sugar diet (HFHSD)}

Bread (30 g)+Biscuits (30 g)+Vanaspati ghee (3 ml)+Coconut oil (1 ml) $25 \%$ fructose was added in drinking water bottle.

These diets were fed along with normal diet for a total period of 6 weeks to rats.

\section{Experimental protocols}

In the HFHSD model, the animals were divided into five groups and each group composed of six animals (Table 1).

All the treatments were carried out for 42 days. Before and after the treatment, the animals were fasted for $2 \mathrm{~h}$ to improve the absorption rate. Parameters studied for this test were body weights, blood glucose, and total high-density lipoprotein cholesterol levels.

\section{RESULTS}

- Morphology (Table 2)

- Consistency and color (Table 3)

- Practical and percentage yield (Table 4)

- Screening of powder (Table 5)

- Phytochemical screening: There is the presence of different phytochemicals in hydroalcoholic extract T1, T2, T3, T4, and T5 (Table 6).
Table 10: HDL level (mg/dl)

\begin{tabular}{lllll}
\hline Group & $\mathbf{0}^{\text {th }}$ day & ${\mathbf{7}^{\text {th }}}^{\text {day }}$ & $\mathbf{1 4}^{\text {th }}$ day & $\mathbf{2 1}^{\text {th }}$ day \\
\hline NC & $46.67 \pm 1.64$ & $48.17 \pm 1.17$ & $48.66 \pm 2.25$ & $50.00 \pm 1.90$ \\
PC & $48.67 \pm 2.74$ & $49.34 \pm 2.34$ & $49.83 \pm 1.84$ & $50.83 \pm 1.48$ \\
STD & $46.16 \pm 2.48^{*}$ & $49.16 \pm 2.13$ & $50.83 \pm 2.48^{* *}$ & $50.5 \pm 1.51$ \\
Test & $50.5 \pm 2.48$ & $57.00 \pm 3.35$ & $55.83 \pm 3.12$ & $54.55 \pm 2.58$ \\
\hline
\end{tabular}

All values are mean \pm standard error of mean, $n=6 .{ }^{*} \mathrm{p}<0.05,{ }^{* *} \mathrm{p}<0.01$ when compared to positive control group. (Following repeated measures ANOVA (parametric methods, using Dunnett's test). HDL: High-density lipoprotein (Graph 3)

Table 11: LDL level (mg/dl)

\begin{tabular}{lllll}
\hline Group & $\mathbf{0}^{\text {th }}$ day & $\mathbf{7}^{\text {th }}$ day & $\mathbf{1 4}^{\text {th }}$ day & $\mathbf{2 1}^{\text {th }}$ day \\
\hline NC & $73.00 \pm 2.28$ & $71.16 \pm 1.72$ & $68.16 \pm 2.04$ & $69.5 \pm 1.76^{*}$ \\
PC & $49.5 \pm 3.08$ & $56.66 \pm 2.94$ & $66.16 \pm 2.92$ & $75.16 \pm 3.48$ \\
STD & $43.16 \pm 2.31$ & $48.67 \pm 2.58$ & $53.5 \pm 1.76^{* *}$ & $54.34 \pm 2.59^{*}$ \\
Test & $43.33 \pm 1.87$ & $47.83 \pm 2.14$ & $51.00 \pm 3.03^{* *}$ & $53.34 \pm 2.43^{* *}$
\end{tabular}

All values are mean \pm standard error of mean, $n=6$. ${ }^{*} p<0.05,{ }^{* *} p<0.01$ when compared to positive control group. (Following repeated measures ANOVA (parametric methods, using Dunnett's test). LDL: Low-density lipoprotein (Graph 4)

Table 12: CHL level (mg/dl)

\begin{tabular}{lllll}
\hline Group & $\mathbf{0}^{\text {th }}$ day & $\mathbf{7}^{\text {th }}$ day & $\mathbf{1 4}^{\text {th }}$ day & $\mathbf{2 1}^{\text {th }}$ day \\
\hline NC & $140.34 \pm 3.67$ & $146.17 \pm 3.31$ & $150.34 \pm 3.45$ & $153.5 \pm 2.95^{* *}$ \\
PC & $146.00 \pm 1.42$ & $153.5 \pm 2.58$ & $170.66 \pm 4.58$ & $192.5 \pm 2.74$ \\
STD & $148.00 \pm 3.46$ & $154.33 \pm 1.86^{*}$ & $170.34 \pm 3.07$ & $182.00 \pm 4.60$ \\
Test & $156.00 \pm 2.36$ & $169.66 \pm 3.15$ & $174.67 \pm 2.43$ & $183.5 \pm 2.50$ \\
All values are mean \pm standard error of mean, $\mathrm{n}=6 .{ }^{*} \mathrm{p}<0.05,{ }^{* *} \mathrm{p}<0.01$ \\
when compared to positive control group. (Following repeated measures \\
ANOVA (parametric methods, using Dunnett's test) (Graph 5)
\end{tabular}

- Antihyperlipidemic activity of polyherbal formulation from diet-induced model on experimental rats Acute toxicity studies $\left(L_{50}\right)$ : In both Phase I and Phase II procedures, none of the animal mortal or any signs of behavioral changes or show any toxicity on the single administration of Healthcare Administration (2000 mg/kg p.o.). Thus, $300 \mathrm{mg} / \mathrm{kg}$ dose was selected for the present study (Table 7).

\section{Evaluation parameters}

- $\quad$ Effect on feed (g) and water (ml) intake (Table 8)

- $\quad$ Effect on body weight (g) (Table 9)

- Effect on HDL level (mg/dl) (Table 10)

- $\quad$ Effect on LDL level (mg/dl) (Table 11)

- $\quad$ Effect on CHL level (mg/dl) (Table 12)

- $\quad$ Effect on blood glucose level (mg/dl) (Table 13)

\section{Graphical representation}

- Effect on total feed and water intake

- Effect on body weight

- Effect on HDL level 


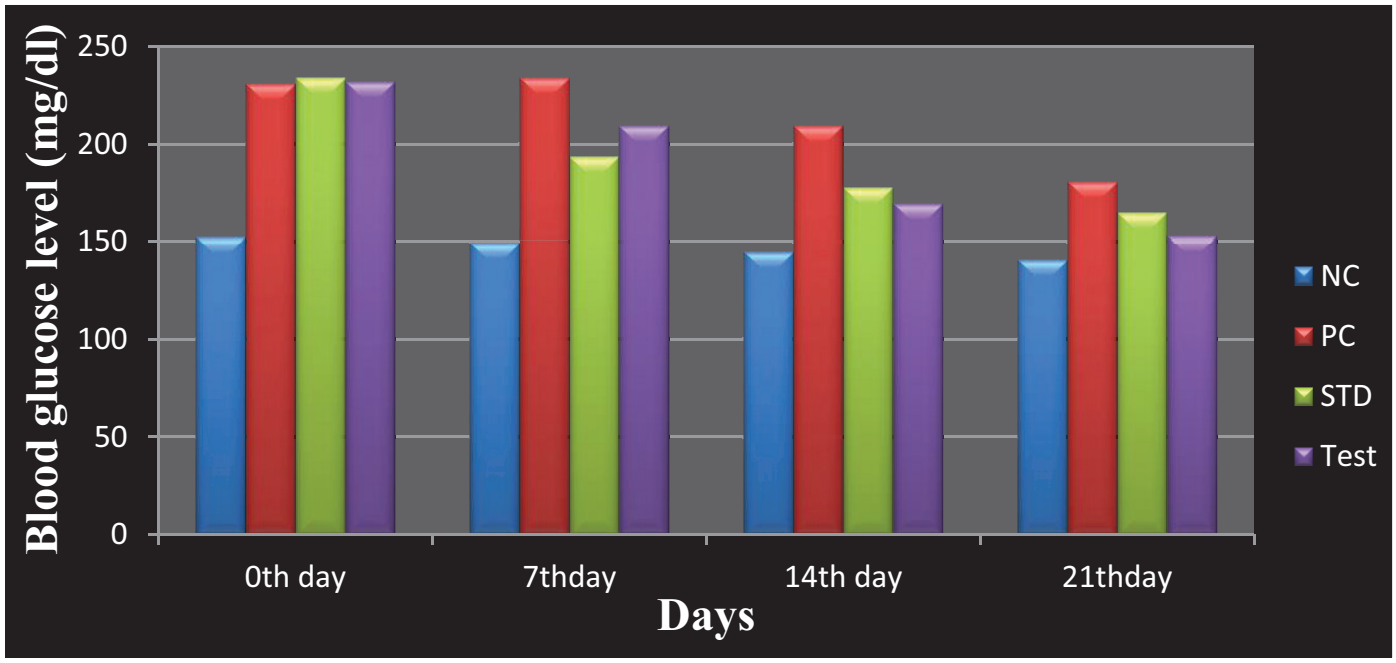

Graph 6: Effect of high-fat high-sugar diet, atorvastatin, and Cordia dichotoma on blood glucose level. Values are expressed as mean \pm standard deviation; $(n=6)$. All values are mean \pm standard error of mean, $n=6$. ${ }^{*} p<0.05,{ }^{* *} p<0.01$ when compared to positive control group. Following repeated measures ANOVA parametric methods, using Dunnett's test. NC: Normal control group, PC: Positive control group or high-fat high-sugar diet group, standard: ND+high-fat high sugar (HFHS)+atorvastatin (2.1 mg/kg/day), test control: ND+HFHS polyherbal formulation $(300 \mathrm{mg} / \mathrm{kg} / \mathrm{day})$

Table 13: Blood glucose level (mg/dl)

\begin{tabular}{llll}
\hline Group & $\mathbf{0}^{\text {th }}$ day & $\mathbf{7}^{\text {th }}$ day & $\mathbf{1 4}^{\text {th }} \mathbf{d a y}^{\text {th }} \mathbf{d a y}$ \\
\hline NC & $152.5 \pm 1.87^{* *}$ & $149.5 \pm 1.87^{* *}$ & $144.84 \pm 2.13^{* *}$ \\
PC & $230.83 \pm 2.31$ & $234.00 \pm 2.60$ & $209.34 \pm 5.16$ \\
STD & $233.84 \pm 4.84$ & $193.67 \pm 6.98^{*}$ & $177.83 \pm 3.43$ \\
Test & $232.00 \pm 5.97$ & $209.34 \pm 6.12$ & $180.84 \pm 10.18$ \\
\hline
\end{tabular}

All values are mean \pm standard error of mean, $n=6 .{ }^{*} p<0.05,{ }^{* *} \mathrm{p}<0.01$ when compared to positive control group.

(Following repeated measures ANOVA (parametric methods, using Dunnett's test)

- Effect on LDL level

- Effect on CHL level

- Effect on blood glucose level

\section{DISCUSSION}

The study was carried out to evaluate antihyperlipidemic activity of polyherbal formulation (T1, T2, T3, T4, and T5) in HFHSD-induced model of rats.

The coarse powder of the shed dried part of the plant was subjected to extraction using Soxhlet apparatus. The plant material was extracted with hydroalcoholic solvent system (1:1). The obtained practical yield of extract sequentially (T1, T2, T3, T4, T5) was $12.801 \mathrm{~g}, 11.502 \mathrm{~g}$, $13.200 \mathrm{gm}, 15.020 \mathrm{~g}$, and $14.250 \mathrm{~g}$ or percentage yield of extract was $14.94 \%, 12.50 \%, 15.20 \%, 16.25 \%$, and $13.65 \%$.

After the extraction, pharmacognostical and phytochemical screening was done. The lipid-lowering activity of polyherbal formulation (T1, T2, $\mathrm{T} 3$, T4, and T5) may be attributed to the phytoconstituents present such as alkaloids, carbohydrates, steroids, proteins, tannins, carbohydrates, flavonoids, phenols, glycosides, and triterpenes.

In acute oral toxicity study, there were no behavioral changes seen up to $4 \mathrm{~h}$ and no mortality was observed up to the end of $24 \mathrm{~h}$ even at the maximum tested dose level of $2000 \mathrm{mg} / \mathrm{kg}$ per oral. It was considered maximum safe dose.

The study was conducted by measuring various parameters, namely, daily feed intake $(\mathrm{g})$, water intake $(\mathrm{ml})$, body weight $(\mathrm{g})$, lipid profile HDL, LDL, CHL level (mg/dl), and blood glucose level (mg/dl).

\section{CONCLUSION}

We can say that polyherbal formulations (T1, T2, T3, T4, and T5) have hypoglycemic activity and significantly improve lipid profile levels in diet-induced experimental rats. Results showed significant decrease in blood glucose level and serum lipid profile such as TC, LDL, and increasing serum HDL level, so could be useful in the treatment of hypolipidemia as mentioned in traditional medicine. However, further studies required to isolate the phytochemicals those responsible for hypolipidemic activity.

\section{ACKNOWLEDGMENTS}

The authors would like to thank Dr. Raghvendra Dubey, Principal of College of Pharmacy, Indore, Madhya Pradesh, for supporting us for the completion of this research work.

\section{AUTHORS' CONTRIBUTIONS}

All the authors have equally contributed

\section{CONFLICTS OF INTEREST}

The authors declare that there are no conflicts of interest.

\section{REFERENCES}

1. Fattepur S, Nilugal CK, Rajendran R, Asmani F, Yusuf E. Antihyperlipidemic activity of methanolic extract of Boesenbergia pandurata (finger root) in experimental induced hypercholestrolemic sprague dawley rats. Asian J Pharm Clin Res 2018;11:8

2. Verma N. Introduction to hyperlipidemia and its treatment: A review. Int J Curr Pharm Res 2017;9:6-14.

3. Nouh F, Omar M, Younis M. Risk factors and management of hyperlipidemia (review). Asian J Cardiol Res 2019;2:1-10. 
4. Venkateshan S, Subramaniyan V, Chinnasamy V, Chandiran S. Antioxidant and anti-hyperlipidemic activity of Hemidesmus indicus in rats fed with high-fat diet. Avicenna J Phytomed 2016;6:516-25.

5. Iyer A, Panchal S, Poudyal H, Brown L. Potential health benefits of Indian spices in the symptoms of the metabolic syndrome: A review. Indian J Biochem Biophys 2009;46:467-81.

6. Lankin VZ, Tikhaze AK, Kukharchuk VV, Konovalova GG, Pisarenko OI, Kaminnyi AI, et al. Antioxidants decreases the intensification of low density lipoprotein in vivo peroxidation during therapy with statins. Mol Cell Biochem 2003;249:129-40.

7. Sarvesh CN, Fernandes J. Evaluation of antihyperlipidemic activity of leaves of Achyranthes aspera Linn. Using hyperlipidemic rats. Asian J Pharm Clin Res 2017;10:211-5.

8. Mamun MA, Hasan N, Shirin F, Belal MH, Khan MA, Tasnin MN, et al. Antihyperglycemic and antihyperlipidemic activity of ethanol extract of garlic (Allium sativum) in streptozotocin-induced diabetic mice. Int J Med Health Res 2017;3:63-6.

9. Keshetty V, Pabba S, Gudipati R, Kandukuri JM, Allenki V. Antihyperlipidemic activity of methanolic extract of garlic (Allium sativum L.) in triton X-100 induced hyperlipidemic rats. J Pharm Res 2009;2:777-80.

10. Jain RC, Vyas CR. Garlic and alloxan induced diabetic rabbits. Am J Clin Nutr 1975;28:684-5.

11. Bais S, Singh GS, Sharma R. Antiobesity and hypolipidemic activity of Moringa oleifera leaves against high fat diet-induced obesity in rats. Adv Biol 2014;2014:157895.
12. Jain PG, Patil SD, Haswani NG, Girase MV, Surana SJ. Hypolipidemic activity of Moring a oleifera Lam., moringaceae, on high fat diet induced hyperlipidemia in albino rats. Braz J Pharmacogn 2010;20:969-73.

13. Harini S, Adilaxmamma K, Mohan EM, Srilatha C, Raj MA. Antihyperlipidemic activity of chickpea sprouts supplementation in ovariectomy induced dyslipidemia in rats. J Ayurveda Integr Med 2015;6:104-10.

14. Sikarwar MS, Patil MB. Antihyperlipidemic activity of Hibiscus rosa-sinensis Linn. ethanolic extract fractions. Int J Health Allied Sci 2015;4:73-8

15. Jyoti S, Kumar PP, Kaur CD. Effect of Quisqualis indica extract on cholesterol diet induced hyperlipidemia in rats. Res J Pharmacol Pharmacodyn 2013;5:317-20.

16. Sahu JJ, Patel PK, Dubey B. Effects of methanolic extracts of Quisqualis indica (aerial parts) on passive smoking induced hyperlipidemia in rats. Asian J Pharm Tech 2013;3:26-9.

17. Bairagi VA, Sadu N, Senthilkumar KL, Ahir Y. Antidiabetic potential of Quisqualis indica linn in rats. Int J Pharm Phytopharmacol Res 2012;1:16671.

18. Bisht A, Madhav NV, Upadhyaya K. Screening of polyherbal formulation for its potential anti-hyperlipidemic and antioxidant activity. J Pharmacogn Phytochem 2015;3:134-9.

19. Sharma S, Khare S, Dubey BK, Joshi A, Jain A. Analgesic activity of polyherbal formulation in experimental rats by acetic acid induced hot plate model. J Drug Deliv Ther 2019;9:276-80. 